\title{
Recurrence of SARS-CoV-2 viral RNA in recovered COVID-19 patients: a narrative review
}

\author{
Thi Loi Dao ${ }^{1,2,3} \cdot$ Van Thuan Hoang ${ }^{1,2,3} \cdot$ Philippe Gautret $^{1,2}$ (1) \\ Received: 10 September 2020 / Accepted: 23 October 2020 / Published online: 28 October 2020 \\ (C) Springer-Verlag GmbH Germany, part of Springer Nature 2020
}

\begin{abstract}
Many studies have shown that re-positive tests for SARS-CoV-2 by RT-PCR in recovered COVID-19 patients are very common. We aim to conduct this review to summarize the clinical and epidemiological characteristics of these patients and discuss the potential explanations for recurrences, the contagiousness of re-detectable positive SARS-CoV-2 virus, and the management of COVID-19 patients after discharge from hospital. The proportion of re-positive tests in discharged COVID-19 patients varied from 2.4 to $69.2 \%$ and persisted from 1 to 38 days after discharge, depending on population size, age of patients, and type of specimens. Currently, several causes of re-positive tests for SARS-CoV-2 in recovered COVID-19 patients are suggested, including false-negative, false-positive RT-PCR tests; reactivation; and re-infection with SARS-CoV-2, but the mechanism leading to these re-positive cases is still unclear. The prevention of re-positive testing in discharged patients is a fundamental measure to control the spread of the pandemic. In order to reduce the percentage of false-negative tests prior to discharge, we recommend performing more than two tests, according to the standard sampling and microbiological assay protocol. In addition, specimens should be collected from multiple body parts if possible, to identify SARS-CoV-2 viral RNA before discharge. Further studies should be conducted to develop novel assays that target a crucial region of the RNA genome in order to improve its sensitivity and specificity.
\end{abstract}

Keywords COVID-19 $\cdot$ SARS-CoV-2 $\cdot$ Recurrence $\cdot$ Discharge $\cdot$ Recovery $\cdot$ PCR $\cdot$ False-negative $\cdot$ False-positive

\section{Introduction}

At the end of December 2019, an epidemic of acute respiratory infections broke out in Wuhan, China. It is caused by a new coronavirus, later named SARS-CoV-2. The disease is highly contagious, with the ability to spread directly through interhuman transmission by the airways, and the epidemic quickly spread globally [1]. The World Health Organization (WHO) declared it a Public Health Emergency of International Concern on 30 January 2020, and then a Global Pandemic on 11 March 2020, less than 3 months after

Philippe Gautret

philippe.gautret@club-internet.fr

1 IRD, AP-HM, SSA, VITROME, Institut Hospitalo-Universitaire Méditerranée Infection, Aix Marseille University, 19-21 Boulevard Jean Moulin, 13385, Marseille Cedex 05, France

2 IHU-Méditerranée Infection, Marseille, France

3 Thai Binh University of Medicine and Pharmacy, Thai Binh, Vietnam its appearance. At the time of writing, the COVID-19 pandemic has affected 213 countries and territories worldwide and has caused 848,929 deaths out of a total of $25,318,363$ people infected [2].

The pandemic is becoming more complex, and it is increasingly difficult to control the disease, both in terms of morbidity and mortality rate. The outbreak has overwhelmed most countries in the world, even high-income countries with modern and advanced medical systems. While some countries, such as the USA, Brazil, and India, which are facing an increasing number of cases, have not seen a downward trend since the first case, others, such as Japan and France, are facing a resurgence of the disease, with the daily number of new cases tending to be higher than ever before [2].

There is currently no specific vaccine available to prevent the disease, and the effectiveness of antiviral treatment is controversial. Patient management after discharge is another challenge. According to the European Centre for Disease Prevention and Control, the discharge criteria for confirmed COVID-19 [3] cases are the following: 
1. No fever for more than 3 days

2. Significant improvement in respiratory symptoms

3. Lung image showing clear absorption of inflammation

4. No need for hospital care for another pathology

5. At least two consecutive negative RT-PCR tests in respiratory samples (with samples taken at least $24 \mathrm{~h}$ apart). Testing at a minimum of 7 days after the first positive RTPCR test is recommended for patients who clinically improve earlier.

6. Appearance of specific $\operatorname{IgG}$ when a serological test is available

Many studies have shown that a re-positive test for the virus using RT-PCR in recovered patients is very common [4-69]. We aim to conduct this review to summarize the clinical and epidemiological characteristics of patients and discuss the potential explanations for these recurrences, the contagiousness of re-detectable SARS-CoV-2 virus in recovered patients, and the management of COVID-19 patients after discharge from hospital.

\section{Clinical and demographic characteristics of re-positive COVID-19 patients after recovery}

Early in February 2020, Lan et al. reported the first four Chinese patients who had tested re-positive during their convalescent period [4]. To date, many other studies have reported re-detectable SARS-CoV-2 tests through RT-PCR during recovery periods of COVID-19 patients [5-69]. Most studies were conducted in China. The proportion of re-positive patients among discharged COVID-19 patients varied from 2.4 to $69.2 \%$ and lasted from 1 to 38 days after discharge, depending on population size, age of patients, and type of specimens [4-65] (Table 1). Age of re-positive patients after discharge ranged from 0 to 91 years old. Males accounted for 26.7$73.3 \%$ of patients. The majority of patients who tested repositive were asymptomatic or had mild symptoms, but some patients progressed critically and died [5]. Table 1 details the characteristics of re-positive patients with COVID-19 after discharge.

In a survey of 126 discharged patients in the Tumor Center at the Union Hospital in Wuhan, China, a proportion of 3/126 (2.4\%) were re-detected positive for SARS-CoV-2 during their recovery period [6]. All three patients were asymptomatic, but the serum lactate dehydrogenase and C-reactive protein levels were increased in two of the patients. They had no contact with any other COVID-19 patients or people with respiratory symptoms after their discharge. In addition, no infected family members were reported [6].

According to the South Korea Center for Disease Control, up to 19 April 2020, 292/8922 (3.3\%) patients who had been discharged following COVID-19 had re-detectable SARSCoV-2 during the recovery period $[7,8]$. The time between discharge and the first re-positive test ranged between 1 and 35 days, and the time between the onset of initial symptoms and testing positive after discharge ranged between 8 and 82 days [7, 8]. Most patients were aged 20-29 years (24.0\%), followed by those aged $50-59$ years $(16.8 \%), 30-39$ years (14.0\%), 60-69 years (10.6\%), and over 80 years $(8.2 \%)$ [7, $8]$. The clinical and epidemiological investigation showed that $44.7 \%$ of re-positive patients had minor symptoms, including fever, cough, and sore throat at re-admission $[7,8]$.

Mei et al. conducted a survey of 651 recovered COVID-19 patients in Wuhan, China [9]. Of these patients, 23 (3.5\%) were found to be re-positive by RT-PCR testing. The median time between discharge from hospital and the re-positive test was between 4 and 38 days. A total of 15/23 (65.2\%) repositive patients were asymptomatic. Eight $(34.8 \%)$ had at least one symptom associated with active COVID-19, as follows: six (26.1\%) were febrile, two (8.7\%) reported a cough, one reported $(4.3 \%)$ dyspnea and chest tightness. Concerningly, it should be noted that $11(47.8 \%)$ patients were negative for both IgG and IgM antibodies against SARS-CoV-2 virus at the time of the positive PCR re-test [9].

A prospective cohort study carried out by Zheng et al. was conducted on 285 adult COVID-19 patients in Guangdong, China [10]. Surveillance following discharge reported 27 (9.5\%) patients who tested re-positive. No significant factors regarding socio-demographic characteristics, comorbidities, clinical presentation at initial hospitalization, or chest CT scans were observed between these patients and the control group (which was still negative during the recovery period). However, during the initial hospitalization, the viral load and eosinophil count of patients who later re-tested positive were higher, while lactate dehydrogenase was lower compared to controls [10].

Deng et al. conducted a survey among 561 discharged COVID-19 patients in Chongqing, China, on January and 10 March 2020 [11]. These patients were required to continue quarantine at home for at least 14 days after being discharged from hospital. They also had no contact with any other COVID-19 patients or people with respiratory symptoms. A total of 61 patients (10.6\%) re-tested positive for SARS-CoV2 by RT-PCR. The duration of the re-positive status ranged from 3 to 35 days, with 47/61 (77.0\%) testing positive within less than 14 days. In addition, no positive cases were reported among their family members [11].

Another study reported that $11.0 \%$ (20/182) of recovered COVID-19 Chinese patients were later identified to be repositive for SARS-CoV-2 during their recovery period, although all of them were asymptomatic at the time of retesting [12]. The epidemiological survey showed no significant differences in sex between those who re-tested positive and those who remained negative. Patients under the age of 18 


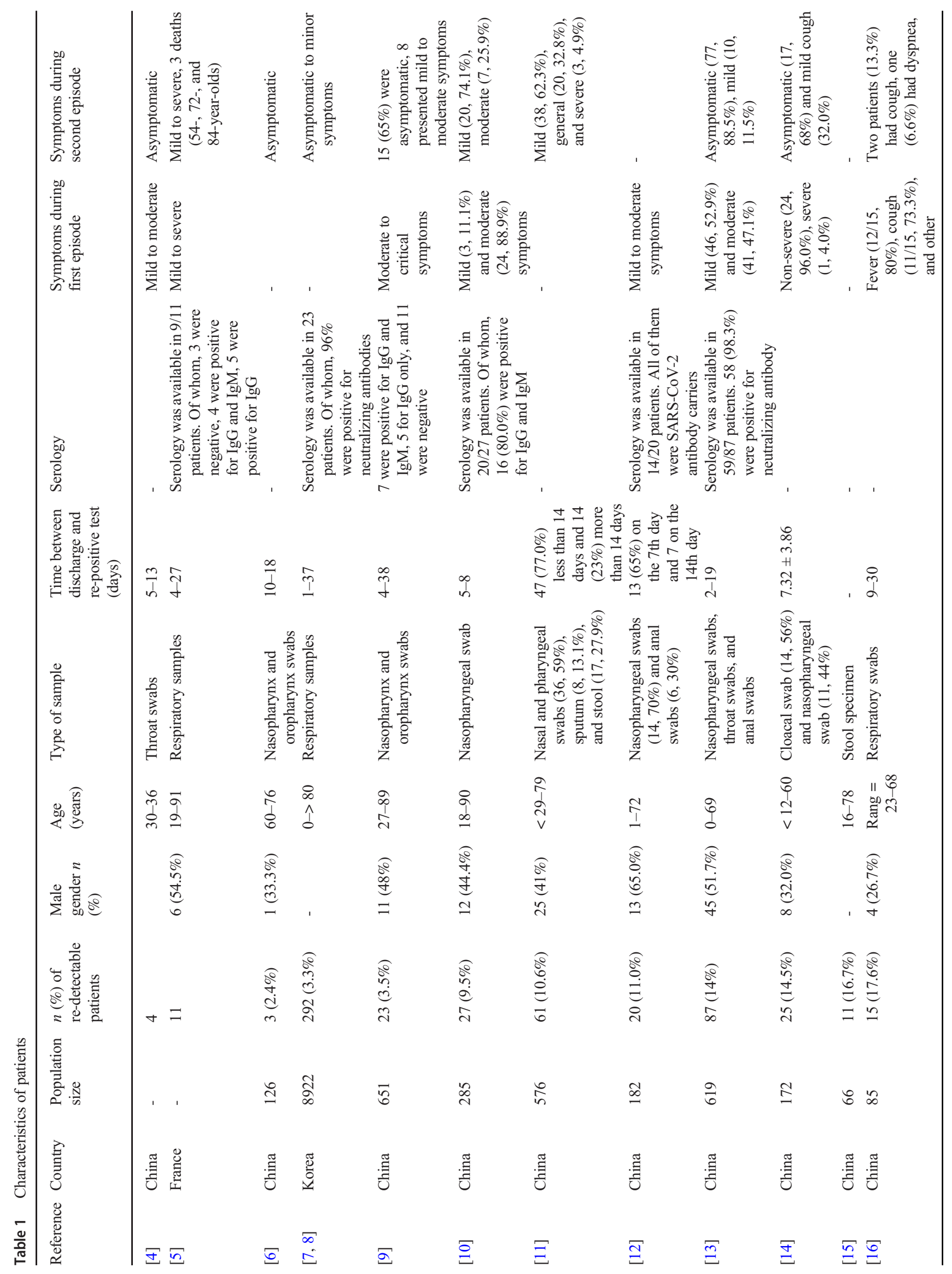




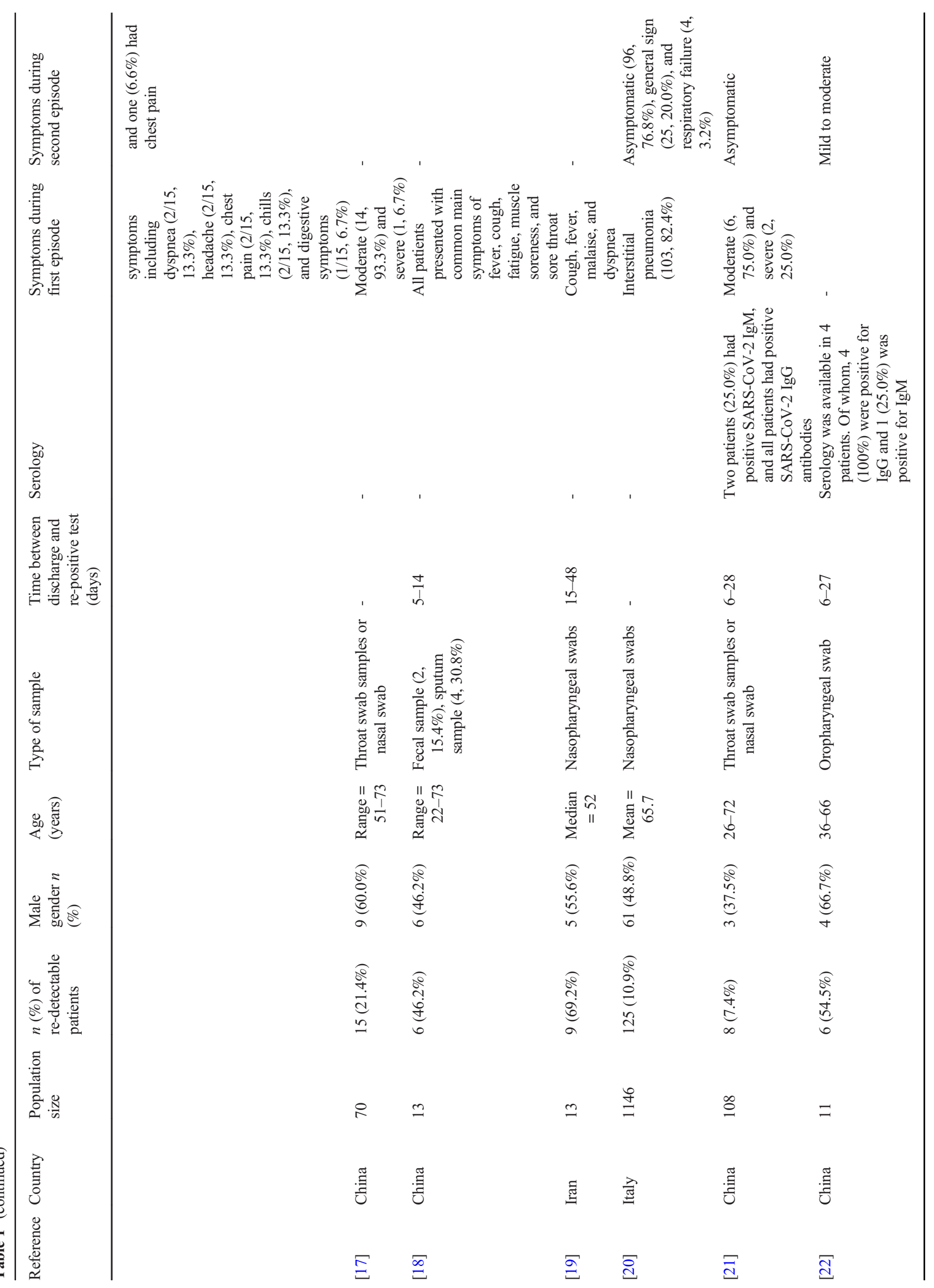




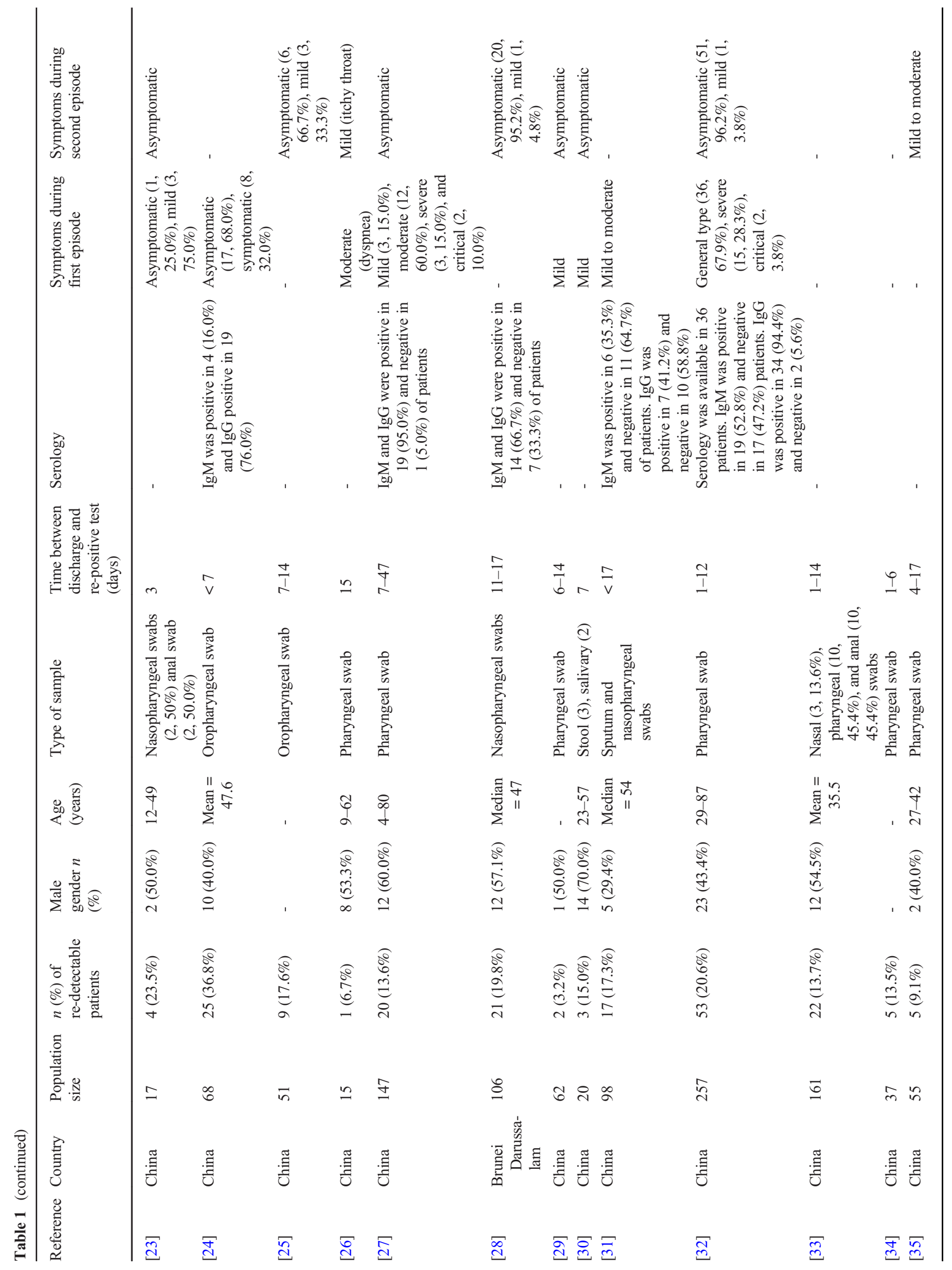




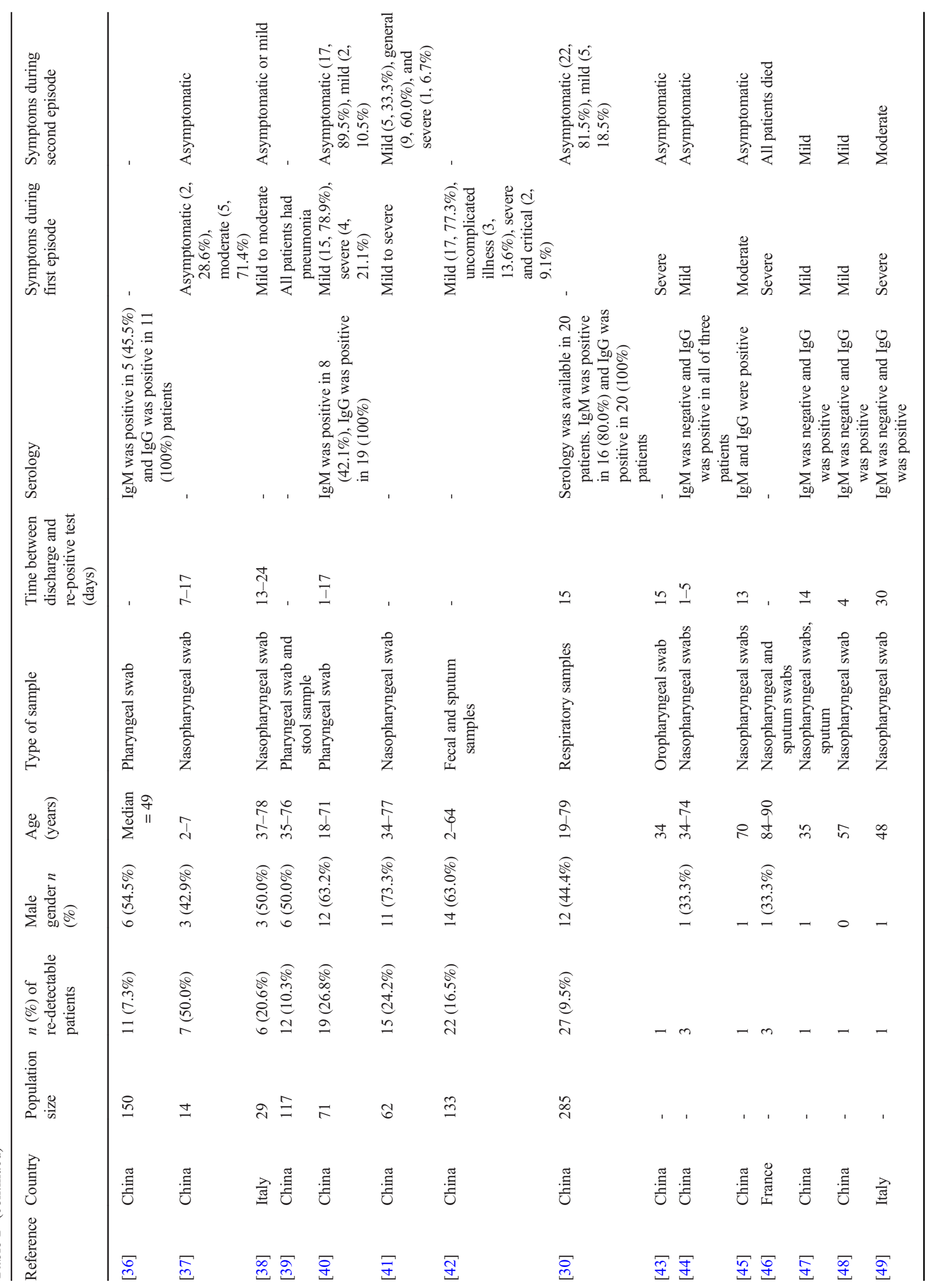




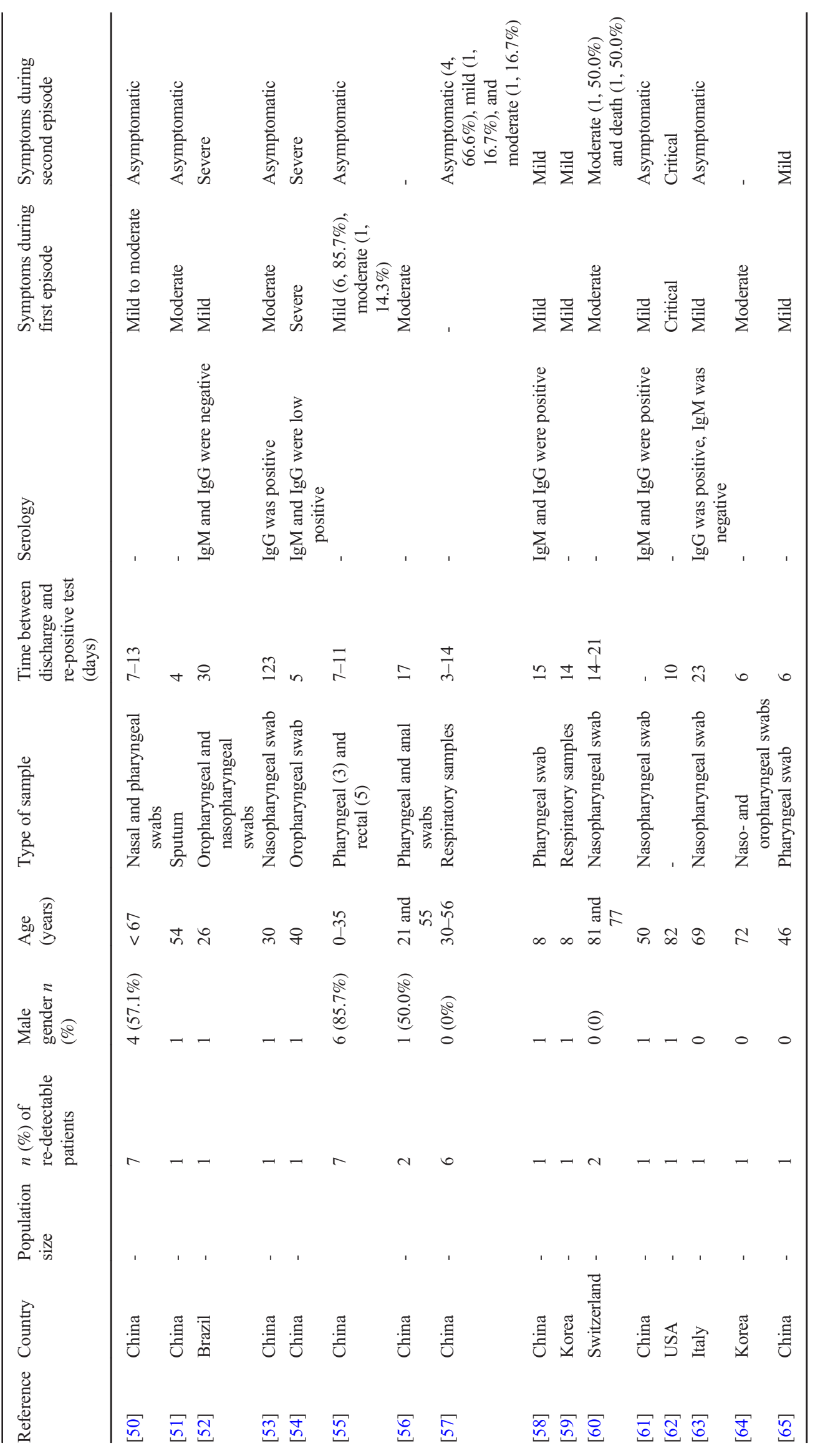


had a higher proportion of re-positive tests than average. In addition, none of the patients who were severely ill at the time of their initial hospitalization had re-positive results. However, serological tests revealed that these patients were positive for antibodies to the SARS-CoV-2 virus and most of them had turned negative by the time of the later RT-PCR test [12].

In a survey by $\mathrm{Lu}$ et al., conducted among 619 discharged COVID-19 patients in Guangdong, China, 87 patients (14.0\%) re-tested positive during their recovery period [13]. The duration between discharge from hospital and the time of the re-positive test ranged between 6 and 28 days. Compared to discharged patients who remained negative, these patients were younger. At the time of their initial hospitalization, they had a less-severe clinical presentation and the length of their hospitalization was shorter. A total of 36 positive samples by RT-PCR (14 nasopharyngeal, three throat, and 19 anal swabs) were inoculated into a Vero-E6 cell line for culture, but no live viruses could be cultured. All re-positive case samples were unsuccessfully sequenced [13].

Yuan et al. showed that $14.5 \%$ (25/172) of Chinese patients, including six children under the age of 12 , returned to the hospital after their discharge due to re-positive RT-PCR test for the SARS-CoV-2 virus [14]. During their first hospitalization, these patients presented with common symptoms of non-severe types of the disease. Only 8/25 (32.0\%) patients had a mild cough at the time of their second admission to hospital. Furthermore, the CT scan results showed that most of original lesions had improved or had not worsened compared with previous results. The RT-PCR results of these patients reverted to negative in both nasopharyngeal swab and rectal swab samples after a mean of 2.73 days in hospital. These patients remained in the hospital for a prolonged observation. On the other hand, no specific differences in levels of laboratory parameters before being discharged following the initial hospitalization were observed between these 25 patients and the remaining 147 who remained negative after discharge [14].

In a retrospective study conducted by Ling et al., which included 66 patients following their hospitalization in Shanghai, China, stool samples from 11 (16.7\%) patients tested positive [15]. The authors showed that the clearance of viral RNA in stool samples was delayed compared to oropharyngeal swabs. In comparison with patients who re-tested negative, people who continued to be positive for fecal viral RNA had no statistically significant differences in inflammatory indicators [15].

$\mathrm{Li}$ et al. conducted a study on chest CT scan evaluations among COVID-19 patients with a positive RT-PCR re-test following their discharge in Sichuan, China [16]. A total of $15 / 85(17.6 \%)$ recovered patients were re-detectable for SARS-CoV-2 and were included in the survey. At the time of their initial hospitalization, these patients generally had mild symptoms such as fever and a cough. Most of them were asymptomatic at the time of their second admission. The authors showed that no radiological features or changes were observed in these patients [16].

In another study conducted on 70 Chinese patients, a total of $15(21.4 \%)$ were positive for SARS-CoV-2 after two consecutive negative results [17]. Compared to patients who remained negative, re-positive patients were more likely to be older (median age $=64$ versus 57 years, $p=0.093$ ) and had a significantly longer nucleic acid conversion time (36 versus 21 days; $p<$ 0.001). Most of these 15 patients experienced a remission of symptoms and radiographic features [17].

Between April 6 and May 14, 2020, 11 French patients between the ages of 19 and 91 were identified as having recurrent COVID-19 [5]. These patients were readmitted to hospital between 4 and 27 days after their initial discharge. The median duration of symptoms ranged from 13 to 41 days and from 7 to 29 days for the first and second episodes, respectively. A total of seven patients (older patients with comorbidities) required intensive care for both episodes because of critical disease. Notably, 3/11 (27.3\%) patients died during their second hospitalization due to the recurrence of acute respiratory distress syndrome (two patients) and worsening chronic right heart failure (one patient) [5]. Patients with uncontrolled diabetes at the time of their initial diagnosis of COVID-19 are at an increased risk of re-infection $[5,11]$.

In a survey of 13 discharged COVID-19 patients in Yiwu, China, sputum samples from four $(30.8 \%)$ re-tested positive between 5 and 14 days after their discharge [18]. In particular, one re-positive patient was able to meet the discharge criteria again, but the RT-PCR results of SARS-CoV-2 returned positive following his second discharge [18].

To date, the highest ratio of re-positive tests for SARSCoV-2 following discharge has been reported in a study by Habibzadeh on 9/13 (69.2\%) recovered patients in Iran [19]. These patients presented mild to moderate symptoms with fever, cough, fainting, and dyspnea during the initial hospitalization. The re-test was found to be positive between 22 and 54 days after the initial onset of symptoms and between 15 and 48 days after the complete resolution of their symptoms [19].

\section{Potential cause of re-detectable positive SARS-CoV-2 virus in recovered patients}

Currently, several causes for re-positive tests for SARS-CoV2 in COVID-19 patients during the recovery period have been described, including false RT-PCR results, intermittent virus shedding, viral reactivation or re-infection with another SARS-CoV-2 strain, or exposing to a contaminated environmental surface after discharge [68]. However, there is a certain possibility of RT-PCR rendering false-negative results before the patients are discharged. 
The false-negative rate of RT-PCR varies from 3 to $41 \%$, according to the type of clinical specimen used $[34,70]$. There are many reasons for false-negative RT-PCR results, including the sensitivity/specificity of the nucleic acid test kit, the sources of samples, and the sampling procedure itself [16, 71]. In a retrospective analysis involving 161 COVID-19 patients, the authors showed that false-negative test results of SARS-CoV-2 viral RNA were mainly caused by poor-quality sampling and that swabs did not contain a sufficient quantity of cellular materials [72]. Furthermore, thermal inactivation also decreases the sensitivity of RT-PCR tests for SARS-CoV-2 [73].

Zou et al. conducted a survey of 257 COVID-19 patients who has been discharged from hospital [32]. These patients were divided into three groups: two consecutive negative (257 cases), three consecutive (37 cases), and four consecutive (5 cases) negative detections. The authors showed that the proportion of re-positive patients was $20.6 \%, 5.4 \%$, and $0 \%$, respectively. Interestingly, the proportion of recurrence positive was significantly lower for those with three consecutive negative results than for those with only two consecutive negative tests at the time of discharge $(p=0.026)$ [32].

In a study conducted on 37 discharged patients, $14(37.8 \%)$ had at least one false-negative result, notably five patients who had two consecutive false-negative results (defined as positivenegative-negative-positive) through RT-PCR for SARS-CoV2 , suggesting an intermittent virus shedding [34]. Danzetta et al., also described 2/81 patients who had a double-negative test in nasopharyngeal and oropharyngeal swabs before having one more positive sample, and who eventually turned negative again (negative-negative-positive-negative). Respiratory shedding of SARS-CoV-2 may be intermittent. Therefore, a single negative swab could be misleading [74].

Nasal swab sampling, rather than throat swabs for SARSCov-2 testing, could reduce the false-negative rate of nucleic acid tests [33]. In contrast, PCR tests can also give falsepositive results, and patients have been diagnosed as repositive when they were actually negative. Possible reasons for false-positive results are contamination during the laboratory procedures and cross-reactivity with other human coronaviruses $[71,75]$. In a study conducted by Katz et al., 3/43 (7.1\%) patients had a false-positive result from an RT-PCR test [76].

Ling et al. conducted a survey of 66 convalescent patients with COVID-19 [15]. The authors showed that viral RNA can be detected in the stool of $54(81.8 \%)$ patients, even in those with negative results from pharyngeal swabs [15]. The mean duration of viral RNA positive in stool samples was longer than pharyngeal swabs (11.0 (9. 16.0) days versus 9.5 (6.0-11.0) days, respectively) [15]. This suggests that an anal swab or stool samples must be used to reduce the number of false-negatives.

However, the possibility cannot be excluded that truly negative discharged patients suffered reactivation or were re-infected with another SARS-CoV-2 strain. A genetic characterization of the viruses must be performed in order to distinguish between re-infection and reactivation of SARS-CoV-2 among re-positive patients. A recent report confirmed re-infection with the virus in a 33-year-old patient for the first time with genetic evidence [53]. The second episode of COVID-19 infection appeared nearly 5 months after the first. The patient was immunocompetent, and SARS-CoV-2 IgG seroconversion was also confirmed 5 days after his second hospitalization [53]. In addition, Zhou et al. described a case of recurrent COVID-19 infection after discharge for insufficient antibody production [54]. The male patient presented with recurrent pneumonia 5 days after being discharged from hospital for COVID-19. He was readmitted to hospital with a fever, lymphocytopenia, elevated levels of ferritin and IL2R, and progression of lesions on the CT scan. The result of the SARS-CoV-2 PCR test was positive. Serological tests showed very low levels of antibodies. This suggested a weak humoral immune response to the virus and a potential reactivation of SARS-CoV-2 [54]. Ye et al. also suggested a possible viral reactivation in 5/55 (9.1\%) discharged patients previously diagnosed with COVID-19 [35]. Of these five patients, four were symptomatic with a fever and biological inflammatory symptoms. Virological factors, host immunity status, and degree of immunosuppression are potential risk factors for the reactivation of the SARS-CoV-2 virus [35]. In another study, Gousseff et al. reported 11 cases of a second active COVID-19 episode with evidence of clinical and virologic criteria, therefore suggesting a possible SARS-CoV-2 virus reinfection or reactivation [5]. Repeated infection with the same human common coronavirus HKU1 and OC43 in a period shorter than 1 year has also been described [77].

Vargas-Ferrer et al. showed that ACE2 (an essential receptor for the entry of SARS-CoV-2) could play an important role in elucidating a re-positive result [78]. A large viral replication in the lower respiratory tract (LRT) is determined by the high expression of this enzyme in LRT compared to that in the upper respiratory tract (URT). This explains why the time the virus remains positive in sputum is longer than in nasopharyngeal samples. Therefore, re-positive results in LRT samples among discharged patients (with negative results from URT swabs) are related to the sampling site [78]. This means that at the time of discharge from the hospital, the virus exists in small amounts in the lower respiratory tract, so the results of the nasopharyngeal swab test were negative. After a while, the virus multiplied, and the patient turned positive again.

Another cause of re-positive tests among discharged patients is that they may have been exposed to a contaminated environmental surface [79]. In a report by Lei et al., five patients who had recovered from severe COVID-19 infection and who had been quarantined in an isolation ward still tested positive. A total of 182 environmental surface samples were collected. Of these, two air samples in the bathroom, two surface samples from floor in the patient's room, two surfaces of patient's mobile phones, and one sample from the patient's 
facemask were found to be positive. Particularly high viral loads were detected in LRT swabs, while URT samples remained negative in one patient [79].

\section{Infectivity of re-detectable positive SARS-CoV-2 virus in recovered patients}

Infectivity depends on viral replication [80]. In the event of a recurrence of SARS-CoV-2, the transmissible capacity depends on the cause of the re-positive test. Furthermore, the ability of the virus to replicate decreases when the amount of viral genetic material in the epithelial cell is low [81]. Theoretically, if the patient is re-infected or if the virus reactivates, these patients are a potential source of transmission. However, to date, re-positive test results among discharged patients have only been performed by PCR on different specimens. The RT-PCR test cannot distinguish between live and dead viruses. To date, no cases of infection among people who had contact with re-positive patients have been reported. In a study on recurrence involving 285 Korean patients who had recovered from COVID-19, no active virus was identified in the samples of these patients [7]. Cultivation tests were all negative and confirmed that the re-positive test for the SARS-CoV-2 virus was likely to be the detection of deactivated viral RNA rather than reactivation or re-infection. A total of 790 contacts were found, and no new confirmed cases were declared [8]. Although the virus was found, not only in the respiratory tract but also in the feces and rectal swabs from re-positive patients, no living virus was found $[55,82,83]$. Evidence of the lack of viral reactivation was also supported by the lack of increase in lung infections revealed by the chest $\mathrm{CT}$ scan $[4,16]$. In addition, the patients with COVID-19 can carry protective antibodies after recovery [84].

However, To et al. described a case of re-infection 142 days after discharge [53], and a decrease in the humoral immune response to the virus was a potential reactivation of SARSCoV-2 [54]. In another study, a possible case of COVID-19 re-infection was reported in a 26-year-old patient residing in Rio de Janeiro, Brazil [52]. More than 40 days after the first mild infection with COVID-19, the patient was admitted to hospital with more potent clinical symptoms. The viral load of the second infection was higher than during the initial hospitalization. Moreover, the antibody against SARS-CoV-2 was detectable only after the second infectious episode. This suggests that the first infection was not sufficient to build up a sufficient immunity response and the patient may have experienced a new infection, rather than a recurrence [52]. A repositive test in symptomatic patients following discharge raises concerns around the recurrence of an active SARS-CoV-2 infection and its transmission [9]. The possible infectiousness of re-positive patients still needs to be established through multiple studies and on larger sample sizes.

\section{Management of COVID-19 patients after discharge}

It is currently unclear whether the recurrence of SARS-CoV2 RNA among COVID-19 patients after discharge could be contagious. Genetic traces of the virus detected by RT-PCR do not correlate with transmission. However, if re-positive patients really do carry the live virus, they could become a potential new source of infection for others. Therefore, it is necessary to monitor the patient after discharge in order to prevent the spread of the pandemic. Since no anti-SARSCoV-2 treatment has yet been approved and no specific vaccine is yet available, quarantine and prevention of infection in the community are crucial to controlling its spread. Currently, the WHO criteria for releasing COVID-19 patients from isolation without requiring re-testing specify 10 days after the onset of symptoms, plus at least three additional symptom-free days in symptomatic patients, and 10 days after a positive test for SARS-CoV-2 in asymptomatic patients [85]. Nevertheless, longer observation and isolation periods should be considered for certain groups of patients. In fact, the time between the onset of the initial symptoms and a positive test after discharge was up to 82 days [8]. Medical examination and SARS-CoV-2 testing also should be carried out at the end of the quarantine period following discharge.

\section{Conclusion}

The recurrence of the SARS-CoV-2 virus in patients who have recovered from COVID-19 after discharge from hospital is common. The cause of this re-positive is still unclear. Preventing re-positive testing among discharged patients is a fundamental way of controlling the spread of the pandemic. In order to reduce the percentage of false-negative tests prior to discharge and to avoid releasing patients who are still positive for SARS-CoV-2, we recommend performing more than two tests according to the standard sampling and microbiological assay protocol [32]. In addition, specimens should be collected from multiple parts of the body if possible, including sputum and stool samples to identify SARSCoV-2 viral RNA before discharge [33]. Therefore, further studies should be carried out to develop novel assays that target a crucial region of the RNA genome to improve its sensitivity and specificity [43].

It is necessary to continue epidemiological surveys on repositive patients in order to monitor their health status and assess their infectivity. In particular, tests on re-positive patients with high viral loads [81], to assess virus culture, should be conducted to more accurately assess the contagiousness of these patients [66]. Family members of COVID-19 patients should also be regularly tested for SARS-CoV-2. 
The high proportion of continuous detection of viral nucleic acids in stool samples despite negative results of RTPCR test in nasopharyngeal swabs [34] suggests that the virus may be transmitted through the digestive tract or retransmitted through aerosols containing viruses. In addition, the presence of live SARS-CoV-2 in the feces reinforces the hypothesis of possible fecal-oral contamination by the virus [86]. Furthermore, there is an urgent need to standardize the process of transporting stool samples from patients with COVID-19 to reduce the risk of further viral transmission. Moreover, fecal samples should be tested regularly in patients with COVID-19, even during the recovery period.

The detection of viral RNA in the air samples and environmental surface indicates the important role of environmental transmission. Good ventilation conditions; strict disinfection of environmental facilities, particularly in hospital wards; and strict hand hygiene must be reinforced to reduce the formation of viral aerosols, cut down the aerosol load, and avoid crossinfection in isolation wards. Emphasis should also be placed on toilet sanitation.

In addition, quarantine and other such policies, even after treatment following the infection and discharge of patients, should be maintained. Large-scale and multi-center studies are recommended to better understand the pathophysiology of the potential recurrence of SARS-CoV-2 in patients with COVID-19. Finally, it is important to re-evaluate the isolation time and standardize it for discharged patients. Criteria for hospital discharge or release from isolation should be updated as experience accumulates and clinical advances are made.

\section{Compliance with ethical standards}

Conflict of interest The authors declare that they have no conflict of interest.

\section{References}

1. World Health Organization (2020) Rolling updates on coronavirus disease (COVID-19). Available at: https://www.who.int/ emergencies/diseases/novel-coronavirus-2019/events-as-theyhappen. Accessed 7 Sept 2020

2. Wordometer. Covid-19 coronavirus pandemic. Available at: https:// www.worldometers.info/coronavirus/. Accessed 7 Sept 2020

3. European Centre for Disease Prevention and Control. Guidance for discharge and ending isolation in the context of widespread community transmission of COVID-19-first update. Available at: https://www.ecdc.europa.eu/sites/default/files/documents/covid19-guidance-discharge-and-ending-isolation-firstupdate.pdf. Accessed 7 Sept 2020

4. Lan L, Xu D, Ye G, Xia C, Wang S, Li Y et al (2020) Positive RTPCR test results in patients recovered from COVID-19. JAMA. https://doi.org/10.1001/jama.2020.2783

5. Gousseff M, Penot P, Gallay L, Batisse D, Benech N, Bouiller K et al (2020) Clinical recurrences of COVID-19 symptoms after recovery: viral relapse, reinfection or inflammatory rebound? J Infect. https://doi.org/10.1016/j.jinf.2020.06.073
6. Du HW, Chen JN, Pan XB, Chen XL, Yixian-Zhang, Fang SF et al (2020) Prevalence and outcomes of re-positive nucleic acid tests in discharged COVID-19 patients. Eur J Clin Microbiol Infect Dis. https://doi.org/10.1007/s10096-020-04024-1

7. Kang Y-J (2020) South Korea's COVID-19 infection status: from the perspective of re-positive test results after viral clearance evidenced by negative test results. Disaster Med Public Health Prep 13. https://doi.org/10.1017/dmp.2020.168

8. KCDA. Findings from investigation and analysis of re-positive cases. Available at: https://www.cdc.go.kr/board/board.es?mid= a30402000000\&bid=0030. Accessed 7 Sept 2020

9. Mei Q, Li J, Du R, Yuan X, Li M, Li J (2020) Assessment of patients who tested positive for COVID-19 after recovery. Lancet Infect Dis. https://doi.org/10.1016/S1473-3099(20)30433-3

10. Zheng J, Zhou R, Chen F, Tang G, Wu K, Li F et al (2020) Incidence, clinical course and risk factor for recurrent PCR positivity in discharged COVID-19 patients in Guangzhou, China: a prospective cohort study. PLoS Negl Trop Dis 14(8):e0008648. https://doi.org/10.1371/journal.pntd.0008648

11. Deng W, Guang T-W, Yang M, Li J-R, Jiang D-P, Li C-Y et al (2020) Positive results for patients with COVID-19 discharged form hospital in Chongqing, China. BMC Infect Dis 20:429. https://doi.org/10.1186/s12879-020-05151-y

12. Yuan B, Liu H-Q, Yang Z-R, Chen Y-X, Liu Z-Y, Zhang K et al (2020) Recurrence of positive SARS-CoV-2 viral RNA in recovered COVID-19 patients during medical isolation observation. Sci Rep 10:11887. https://doi.org/10.1038/s41598-020-68782-w

13. Lu J, Peng J, Xiong Q, Liu Z, Lin H, Tan X et al (2020) Clinical, immunological and virological characterization of COVID-19 patients that test re-positive for SARS-CoV-2 by RT-PCR. EBioMedicine. 59:102960

14. Yuan J, Kou S, Liang Y, Zeng J, Pan Y, Liu L (2020) PCR assays turned positive in 25 discharged COVID-19 patients. Clin Infect Dis. https://doi.org/10.1093/cid/ciaa398

15. Ling Y, Xu S-B, Lin Y-X, Tian D, Zhu Z-Q, Dai F-H et al (2020) Persistence and clearance of viral RNA in 2019 novel coronavirus disease rehabilitation patients. Chin Med J. https://doi.org/10.1097/ CM9.0000000000000774

16. Li C, Luo F, Xie L, Gao Y, Zhang N, Wu B (2020) Chest CT study of fifteen COVID-19 patients with positive RT-PCR retest results after discharge. Quant Imaging Med Surg 10:1318-1324. https:// doi.org/10.21037/qims-20-530

17. Xiao AT, Tong YX, Zhang S (2020) False negative of RT-PCR and prolonged nucleic acid conversion in COVID-19: rather than recurrence. J Med Virol. https://doi.org/10.1002/jmv.25855

18. Li Y, Hu Y, Yu Y, Zhang X, Li B, Wu J et al (2020) Positive result of Sars-Cov-2 in faeces and sputum from discharged patients with COVID-19 in Yiwu, China. J Med Virol. https://doi.org/10.1002/ jmv. 25905

19. Habibzadeh P, Sajadi MM, Emami A, Karimi MH, Yadollahie M, Kucheki M et al (2020) Rate of re-positive RT-PCR test among patients recovered from COVID-19. Biochem Med (Zagreb) 30: 030401. https://doi.org/10.11613/BM.2020.030401

20. Bongiovanni M, Vignati M, Giuliani G, Manes G, Arienti S, Pelucchi L et al (2020) The dilemma of COVID-19 recurrence after clinical recovery. J Infect. https://doi.org/10.1016/j.jinf.2020.08. 019

21. Cao H, Ruan L, Liu J, Liao W (2020) The clinical characteristic of eight patients of COVID-19 with positive RT-PCR test after discharge. J Med Virol. https://doi.org/10.1002/jmv.26017

22. Chen M, An W, Xia F, Yang P, Li K, Zhou Q et al (2020) Clinical characteristics of rehospitalized patients with COVID-19 in China. J Med Virol. https://doi.org/10.1002/jmv.26002

23. Chen Y, Bai W, Liu B, Huang J, Laurent I, Chen F et al (2020) Reevaluation of retested nucleic acid-positive cases in recovered COVID-19 patients: report from a designated transfer hospital in 
Chongqing, China. J Infect Public Health 13:932-934. https://doi. org/10.1016/j.jiph.2020.06.008

24. Liu BM, Yang QQ, Zhao LY, Xie W, Si XY (2020) Epidemiological characteristics of COVID-19 patients in convalescence period. Epidemiol Infect 148:e108. https://doi.org/10.1017/ S0950268820001181

25. Liu C, Ye L, Xia R, Zheng X, Yuan C, Wang Z et al (2020) Chest $\mathrm{CT}$ and clinical follow-up of discharged patients with COVID-19 in Wenzhou City, Zhejiang, China. Ann Am Thorac Soc. https://doi. org/10.1513/AnnalsATS.202004-324OC

26. Qiao X-M, Xu X-F, Zi H, Liu G-X, Li B-H, Du X et al (2020) Repositive cases of nucleic acid tests in discharged patients with COVID-19: a follow-up study. Front Med (Lausanne) 7:349. https://doi.org/10.3389/fmed.2020.00349

27. Tian M, Long Y, Hong Y, Zhang X, Zha Y (2020) The treatment and follow-up of "recurrence" with discharged COVID-19 patients: data from Guizhou, China. Environ Microbiol 22:3588-3592. https://doi.org/10.1111/1462-2920.15156

28. Wong J, Koh WC, Momin RN, Alikhan MF, Fadillah N, Naing L (2020) Probable causes and risk factors for positive SARS-CoV-2 test in recovered patients: evidence from Brunei Darussalam. J Med Virol. https://doi.org/10.1002/jmv.26199

29. Xing Y, Mo P, Xiao Y, Zhao O, Zhang Y, Wang F (2020) Postdischarge surveillance and positive virus detection in two medical staff recovered from coronavirus disease 2019 (COVID-19), China, January to February 2020. Euro Surveill 25. https://doi.org/10. 2807/1560-7917.ES.2020.25.10.2000191

30. Zheng KI, Wang X-B, Jin X-H, Liu W-Y, Gao F, Chen Y-P et al (2020) A case series of recurrent viral RNA positivity in recovered COVID-19 Chinese patients. J Gen Intern Med 35:2205-2206. https://doi.org/10.1007/s11606-020-05822-1

31. Zhu H, Fu L, Jin Y, Shao J, Zhang S, Zheng N et al (2020) Clinical features of COVID-19 convalescent patients with re-positive nucleic acid detection. J Clin Lab Anal e23392. https://doi.org/10. 1002/jcla.23392

32. Zou Y, Wang B-R, Sun L, Xu S, Kong Y-G, Shen L-J et al (2020) The issue of recurrently positive patients who recovered from COVID-19 according to the current discharge criteria: investigation of patients from multiple medical institutions in Wuhan, China. $\mathrm{J}$ Infect Dis. https://doi.org/10.1093/infdis/jiaa301

33. Xie C, Lu J, Wu D, Zhang L, Zhao H, Rao B et al (2020) False negative rate of COVID-19 is eliminated by using nasal swab test. Travel Med Infect Dis 101668. https://doi.org/10.1016/j.tmaid. 2020.101668

34. Wang G, Yu N, Xiao W, Zhao C, Wang Z (2020) Consecutive false-negative rRT-PCR test results for SARS-CoV-2 in patients after clinical recovery from COVID-19. J Med Virol. https://doi. org/10.1002/jmv.26192

35. Ye G, Pan Z, Pan Y, Deng Q, Chen L, Li J et al (2020) Clinical characteristics of severe acute respiratory syndrome coronavirus 2 reactivation. J Infect 80:e14-e17. https://doi.org/10.1016/j.jinf. 2020.03.001

36. Liu T, Wu S, Zeng G, Zhou F, Li Y, Guo F et al (2020) Recurrent positive SARS-CoV-2: immune certificate may not be valid. J Med Virol. https://doi.org/10.1002/jmv.26074

37. Zhao W, Wang Y, Tang Y, Zhao W, Fan Y, Liu G et al (2020) Characteristics of children with reactivation of SARS-CoV-2 infection after hospital discharge. Clin Pediatr (Phila). https://doi.org/10. 1177/0009922820928057

38. Landi F, Gremese E, Rota E, Carfi A, Benvenuto F, Ciciarello F et al (2020) Positive RT-PCR nasopharyngeal swab in patients recovered from COVID-19 disease: when does quarantine really end? J Inf Secur. https://doi.org/10.1016/j.jinf.2020.08.034

39. Ye H, Zhao C, Yang L, Yu W, Leng Z, Sun Y et al (2020) Twelve out of 117 recovered COVID-19 patients retest positive in a single- center study of China. EClinicalMedicine. https://doi.org/10.1016/j. eclinm.2020.100492

40. Li J, Wei X, Tian W, Zou J, Wang Y, Xue W et al (2020) Clinical features of discharged COVID-19 patients with an extended SARSCoV-2 RNA positive signal in respiratory samples. Virus Res. https://doi.org/10.1016/j.virusres.2020.198047

41. Liu J, Lian R, Zhang G, Hou B, Wang C, Dong J et al (2020) Changes in serum virus-specific IgM/IgG antibody in asymptomatic and discharged patients with reoccurring positive COVID-19 nucleic acid test (RPNAT). Ann Med. https://doi.org/10.1080/ 07853890.2020 .1811887

42. Chen C, Gao G, Xu Y, Pu L, Wang Q, Wang L et al (2020) SARSCoV-2-positive sputum and feces after conversion of pharyngeal samples in patients with COVID-19. Ann Intern Med. https:// doi.org/10.7326/M20-0991

43. Dou C, Xie X, Peng Z, Tang H, Jiang Z, Zhong Z et al (2020) A case presentation for positive SARS-CoV-2 RNA recurrence in a patient with a history of type 2 diabetes that had recovered from severe COVID-19. Diabetes Res Clin Pract 166:108300. https://doi. org/10.1016/j.diabres.2020.108300

44. Fu W, Chen Q, Wang T (2020) Letter to the Editor: three cases of redetectable positive SARS-CoV-2 RNA in recovered COVID-19 patients with antibodies. J Med Virol. https://doi.org/10.1002/jmv. 25968

45. Gao G, Zhu Z, Fan L, Ye S, Huang Z, Shi Q et al (2020) Absent immune response to SARS-CoV-2 in a 3-month recurrence of coronavirus disease 2019 (COVID-19) case. Infection. https://doi.org/ 10.1007/s 15010-020-01485-6

46. Lafaie L, Célarier T, Goethals L, Pozzetto B, Grange S, Ojardias E et al (2020) Recurrence or relapse of COVID-19 in older patients: a description of three cases. J Am Geriatr Soc. https://doi.org/10. 1111/jgs. 16728

47. Liu F, Cai Z-B, Huang J-S, Yu W-Y, Niu H-Y, Zhang Y et al (2020) Positive SARS-CoV-2 RNA recurs repeatedly in a case recovered from COVID-19: dynamic results from 108 days of follow-up. Pathog Dis 78. https://doi.org/10.1093/femspd/ftaa031

48. Liu F, Cai Z-B, Huang J-S, Niu H-Y, Yu W-Y, Zhang Y et al (2020) Repeated COVID-19 relapse during post-discharge surveillance with viral shedding lasting for 67 days in a recovered patient infected with SARS-CoV-2. J Microbiol Immunol Infect. https:// doi.org/10.1016/j.jmii.2020.07.017

49. Loconsole D, Passerini F, Palmieri VO, Centrone F, Sallustio A, Pugliese S et al (2020) Recurrence of COVID-19 after recovery: a case report from Italy. Infection. https://doi.org/10.1007/s15010020-01444-1

50. Peng J, Wang M, Zhang G, Lu E (2020) Seven discharged patients turning positive again for SARS-CoV-2 on quantitative RT-PCR. Am J Infect Control 48:725-726. https://doi.org/10.1016/j.ajic. 2020.03.017

51. Zhang J-F, Yan K, Ye H-H, Lin J, Zheng J-J, Cai T (2020) SARSCoV-2 turned positive in a discharged patient with COVID-19 arouses concern regarding the present standards for discharge. Int J Infect Dis 97:212-214. https://doi.org/10.1016/j.ijid.2020.03.007

52. Alonso F de OM, Sabino BD, Guimarães MAAM, Varella RB (2020) Recurrence of SARS-CoV-2 infection with a more severe case after mild COVID-19, reversion of RT-qPCR for positive and late antibody response: case report. J Med Virol. https://doi.org/10. 1002/jmv.26432

53. To KK-W, Hung IF-N, Ip JD, Chu AW-H, Chan W-M, Tam AR, et al. COVID-19 re-infection by a phylogenetically distinct SARScoronavirus-2 strain confirmed by whole genome sequencing. Clin Infect Dis. 2020; ciaa1275. https://doi.org/10.1093/cid/ciaa1275

54. Zhou X, Zhou J, Zhao J (2020) Recurrent pneumonia in a patient with new coronavirus infection after discharge from hospital for insufficient antibody production: a case report. BMC Infect Dis 20:500. https://doi.org/10.1186/s12879-020-05231-z 
55. Zhang B, Liu S, Dong Y, Zhang L, Zhong Q, Zou Y et al (2020) Positive rectal swabs in young patients recovered from coronavirus disease 2019 (COVID-19). J Infect 81:e49-e52. https://doi.org/10. 1016/j.jinf.2020.04.023

56. Dou P, Zhang S, Wang C, Cai L, Liu Z, Xu Q et al (2020) Serial CT features in discharged COVID-19 patients with positive RT-PCR re-test. Eur J Radiol. https://doi.org/10.1016/j.ejrad.2020.109010

57. Jiang M, Li Y, Han M, Wang Z, Zhang Y, Du X (2020) Recurrent PCR positivity after hospital discharge of people with coronavirus disease 2019 (COVID-19). J Inf Secur. https://doi.org/10.1016/j. jinf.2020.03.024

58. Wang H, Li Y, Wang F, Du H, Lu X (2020) Rehospitalization of a recovered coronavirus disease 19 (COVID-19) child with positive nucleic acid detection. Pediatr Infect Dis J 39:e69. https://doi.org/ 10.1097/INF.0000000000002690

59. Yoo SY, Lee Y, Lee GH, Kim DH (2020) Reactivation of SARSCoV-2 after recovery. Pediatr Int. https://doi.org/10.1111/ ped.14312

60. Ravioli S, Ochsner H, Lindner G (2020) Reactivation of COVID19 pneumonia: a report of two cases. J Inf Secur. https://doi.org/10. 1016/j.jinf.2020.05.008

61. Li J, Long X, Fang X, Zhang Q, Hu S, Lin Z et al (2020) SARSCoV-2 positivity in a discharged COVID-19 patient: a case report. Clin Microbiol Infect. https://doi.org/10.1016/j.cmi.2020. 04.032

62. Duggan NM, Ludy SM, Shannon BC, Reisner AT, Wilcox SR (2020) Is novel coronavirus 2019 reinfection possible? Interpreting dynamic SARS-CoV-2 test results through a case report. Am J Emerg Med. https://doi.org/10.1016/j.ajem.2020.06.079

63. Bentivegna E, Sentimentale A, Luciani M, Speranza ML, Guerritore L, Martelletti P (2020) New IgM seroconversion and positive RT-PCR test after exposure to the virus in recovered COVID-19 patient. J Med Virol. https://doi.org/10.1002/jmv. 26160

64. Chae KJ, Jin GY, Lee CS, Lee HB, Lee JH, Kwon KS (2020) Positive conversion of COVID-19 after two consecutive negative RT-PCR results: a role of low-dose CT. Eur J Radiol. https://doi. org/10.1016/j.ejrad.2020.109122

65. Wu F, Zhang W, Zhang L, Wang D, Wan Y (2020) Discontinuation of antiviral drugs may be the reason for recovered COVID-19 patients testing positive again. Br J Hosp Med. https://doi.org/10. 12968/hmed.2020.0156

66. Hoang VT, Dao TL, Gautret P (2020) Recurrence of positive SARS-CoV-2 in patients recovered from COVID-19. J Med Virol. https://doi.org/10.1002/jmv.26056

67. Osman AA, Al Daajani MM, Alsahafi AJ (2020) Re-positive COVID-19 PCR test: could it be a reinfection? New Microbes New Infect 100748. https://doi.org/10.1016/j.nmni.2020.100748

68. Gao Z, Xu Y, Guo Y, Xu D, Zhang L, Wang X et al (2020) A systematic review of re-detectable positive virus nucleic acid among COVID-19 patients in recovery phase. Infect Genet Evol 104494. https://doi.org/10.1016/j.meegid.2020.104494

69. Ulhaq ZS, Soraya GV, Fauziah FA (2020) Recurrent positive SARS-CoV-2 RNA tests in recovered and discharged patients. Rev Clin Esp. S0014-2565(20)30202-2. https://doi.org/10.1016/j. rce.2020.06.012

70. Huang C, Wang Y, Li X, Ren L, Zhao J, Hu Y et al (2020) Clinical features of patients infected with 2019 novel coronavirus in Wuhan, China. Lancet 395:497-506. https://doi.org/10.1016/S01406736(20)30183-5

71. Corman VM, Landt O, Kaiser M, Molenkamp R, Meijer A, Chu DK et al (2020) Detection of 2019 novel coronavirus (2019-nCoV) by real-time RT-PCR. Eurosurveillance 25:2000045. https://doi. org/10.2807/1560-7917.ES.2020.25.3.2000045

72. Zhang Y, Wang C, Han M, Ye J, Gao Y, Liu Z et al (2020) Discrimination of false negative results in RT-PCR detection of
SARS-CoV-2 RNAs in clinical specimens by using an internal reference. Virol Sin 1-10. https://doi.org/10.1007/s12250-02000273-8

73. Pan Y, Long L, Zhang D, Yuan T, Cui S, Yang P et al (2020) Potential false-negative nucleic acid testing results for severe acute respiratory syndrome coronavirus 2 from thermal inactivation of samples with low viral loads. Clin Chem 66:794-801. https://doi. org/10.1093/clinchem/hvaa091

74. Danzetta ML, Amato L, Cito F, Di Giuseppe A, Morelli D, Savini $\mathrm{G}$ et al (2020) SARS-CoV-2 RNA persistence in naso-pharyngeal swabs. Microorganisms. 8(8):1124. https://doi.org/10.3390/ microorganisms 8081124

75. Afzal A (2020) Molecular diagnostic technologies for COVID-19: limitations and challenges. J Adv Res S2090123220301788. https://doi.org/10.1016/j.jare.2020.08.002

76. Katz AP, Civantos FJ, Sargi Z, Leibowitz JM, Nicolli EA, Weed D et al (2020) False-positive reverse transcriptase polymerase chain reaction screening for SARS-CoV-2 in the setting of urgent head and neck surgery and otolaryngologic emergencies during the pandemic: clinical implications. Head Neck. https://doi.org/10.1002/ hed.26317

77. Galanti M, Shaman J (2020) Direct observation of repeated infections with endemic coronaviruses. J Infect Dis. https://doi.org/10. 1093/infdis/jiaa392

78. Vargas-Ferrer J, Zamora-Mostacero V (2020) Re-detectable positive RT-PCR test results in recovered COVID-19 patients: the potential role of ACE2. Disaster Med Public Health Prep 1-4. https:// doi.org/10.1017/dmp.2020.276

79. Lei H, Ye F, Liu X, Huang Z, Ling S, Jiang Z et al (n.d.) SARS$\mathrm{CoV}-2$ environmental contamination associated with persistently infected COVID-19 patients. Influenza Other Respir Viruses. https://doi.org/10.1111/irv.12783

80. Wölfel R, Corman VM, Guggemos W, Seilmaier M, Zange S, Müller MA et al (2020) Virological assessment of hospitalized patients with COVID-2019. Nature 581:465-469. https://doi.org/ 10.1038/s41586-020-2196-x

81. La Scola B, Le Bideau M, Andreani J, Hoang VT, Grimaldier C, Colson P et al (2020) Viral RNA load as determined by cell culture as a management tool for discharge of SARS-CoV-2 patients from infectious disease wards. Eur J Clin Microbiol Infect Dis 39(6): 1059-1061. https://doi.org/10.1007/s10096-020-03913-9

82. Lin W, Xie Z, Li Y, Li L, Wen C, Cao Y et al Association between detectable SARS-COV-2 RNA in anal swabs and disease severity in patients with coronavirus disease 2019. J Med Virol. https://doi. org/10.1002/jmv.26307

83. Zhang W, Du R-H, Li B, Zheng X-S, Yang X-L, Hu B et al (2020) Molecular and serological investigation of 2019-nCoV infected patients: implication of multiple shedding routes. Emerg Microbes Infect 9:386-389. https://doi.org/10.1080/22221751.2020.1729071

84. Bao L, Deng W, Gao H, Xiao C, Liu J, Xue J et al (2020) Lack of reinfection in rhesus macaques infected with SARS-CoV-2. bioRxiv. https://doi.org/10.1101/2020.03.13.990226

85. World Health Organization (2020) Criteria for releasing COVID-19 patients from isolation. Available at: https://www.who.int/newsroom/commentaries/detail/criteria-for-releasing-covid-19-patientsfrom-isolation. Accessed 28 Oct 2020

86. Dergham J, Delerce J, Bedotto M, La Scola B, Moal V Living SARS-CoV-2 in feces suggesting possible fecal-oral contamination. Available at: https://www.mediterranee-infection.com/wpcontent/uploads/2020/04/Dergham-et-al-pr\%C3\%A9print-IHU. pdf. Accessed 28 Oct 2020

Publisher's note Springer Nature remains neutral with regard to jurisdictional claims in published maps and institutional affiliations. 